\title{
Acoustic Assessment of a Precast Factory in Kolkata, India
}

\author{
Rohan S. Wilkho ${ }^{1} \&$ Himadri Guha ${ }^{2}$ \\ ${ }^{1}$ Afcons Infrastructure Limited, India \\ ${ }^{2}$ Jadavpur University, Kolkata, India \\ Correspondence: Rohan Singh Wilkho, M/S Transtonnelstroy Afcons Joint Venture, Howrah, West Bengal, \\ India. E-mail: rohanwilkho@gmail.com
}

Received: November 14, 2017 Accepted: November 26, 2017 Online Published: November 29, 2017

doi:10.5539/jms.v7n4p142 URL: http://doi.org/10.5539/jms.v7n4p142

\begin{abstract}
Sustainable development has various indicators like transport system, economy, land use etc. Quality of life is one of them and protection from noise, especially at workplace plays a prime role in determining it.Numerous literature surveys have revealed that the construction industry ranks second in terms of thestaff being exposed to loud noise and its consequent hazards. A similar situation was observed in a major infrastructure project in Kolkata, India. A questionnaire survey among the workers and a 3D simulation model was created to assess the noise levels. The results revealed that the perceived noise levels were significantly high and exceeded the limits set by concerned authorities. This warranted actions to reduce noise levels. To achieve this, two alternate simulation models were created with altered acoustic properties. The results of these simulations reduced noise to identical levels, which were lower than the limit set. And hence, it was concluded that lower noise levels could not be achieved and was proposed that adopting either of the two would fit the purpose.
\end{abstract}

Keywords: sustainable development, noise hazards, noise level, acoustic insulation

\section{Introduction}

Sustainable development may be defined as one in which the inhabitants enjoy good quality of life and which makes sure not to transfer environmental or health and socio-economic problems to other placed or future generations (Coelho \& Alarcao, 2006). It aims at delivering basic social, economic and environmental services to the inhabitants without endangering the viability of natural, built and social systems upon which the delivery of these services rely upon. Therefore, sustainable development requires a careful balance between sustainable economy, proper housing and health of inhabitants, clean environment, sustainable transport system and efficient land use.

Noise, however disrupts this balance by affecting almost all the elements. Harmful noise, with its negative health impact, is the second largest environmental polluter worldwide (WHO, 2001). And, the overall loudness of environmental noise is on an exponential rise over the years (Chedd, 1981). The World Health Organization (WHO) estimates that the Disability Adjusted Life Years (DALY) lost due to environmental noise are "6000 years for ischemic heart disease, 45,000 years for cognitive impairment of children, 903,000 years for sleep disturbance, 21,000 years for tinnitus and 587,000 years for annoyance" (WHO, 2001). And, Noise Induced Hearing Loss and Noise Induced Tinnitus are significant public health issues (Nelson, Nelson, Concha-Barrientos, \& Fingerhut, 2005). Considering the importance of all these issues, noise protection is an important indicator of sustainable development.

As per the National Institute of Safety and Health (NIOSH), in 2007, nearly 23,000 cases of occupational hearing losses were reported and this accounted for $14 \%$ of all cases of occupational illness in 2007. A study revealed that between 1996 and 2010, around 58\% of the workers experienced abnormal hearing loss owing to noise, and the construction industry saw the second highest number of workers exposed to noise hazards. And the fact that hearing losses are irreversible aggravates the situation.

The practice of recording the exposure to high levels of noise in construction is not new (LaBenz, Cohen, \& Pearson, 1967; Kenney \& Ayer, 1975), yet it continues to remain a major hazard to the staff. Recent estimates suggest that more than half a million construction staff is exposed to harmful noise (Suter, 2002; Lusk, Hong, Ronis, Eakin, Kerr, \& Early, 1999). The results of such and similar studies have prompted institutions like the International Organization for Standardization (ISO), British Standards (BS) and various other Government 
Labour Organizations to concoct stringent clauses regarding occupational noise hazards in their standards which urge organizations worldwide to abide by them. In addition, major construction contracts worldwide also have clauses which place limits to the amount and level of noise exposure.

Even after the presence of such legislation, it is common for construction sites to exceed the noise limits. Construction workers are continuously exposed to loud and impulsive noise, owing to the industry's dependence on heavy machinery (LaBenz, Cohen, \& Pearson, 1967; Kenney \& Ayer, 1975; Kenney \& Ayer, 1975; McClymont \& Simpson, 1989). The exposure to loud noise on one hand leads to threshold shift (in hearing), and with continuous exposure, the recovery time to return to normal also increases (Kantova, 2016; Nixon, Johnson \& Stephenson, 1977). And impulsive noise on the other hand has been found to be more damaging than continuous noise of equal energy (Ward, 1976).

Hence, in order to promote sustainability, it is important to focus on the noise produced in construction works, its effects on the workers and methods to reduce it. This study examines the same for one of the construction projects in Kolkata, India. The project in focus is one of the most popular underground metro projects in India, and the site in focus is a precast concrete factory used to build segmental concrete lining for the underground tunnel. The effects of noise on workers are assessed by the help of a questionnaire survey based on a five point Likert scale and the noise levels are assessed using a simulation software, i-Simpa.

\section{The Factory}

The factory in focus is located on the banks of River Hooghly, a tributary of one of India's holiest rivers, the Ganges. It covers a typical rectangular plot of dimensions $142.00 \mathrm{~m} \times 23.00 \mathrm{~m}$, which has different areas allocated for reinforcement cage manufacturing, segment casting and segment stacking. The segment shutters or moulds, which give the desired shape to the segments, are the predominant noise sources in the factory. These noise sources are positioned in the segment casting area, nearly at the central portion of the factory, which enables the noise to travel to all corners.

In order to produce the segments, concrete is poured in these shutters/moulds using transit mixers. And while, the concrete is being poured in them, in order to achieve a proper finished product, shutter vibrators (fixed to the shutters) are used for compaction. When in use, these vibrators produce an impulsive and loud noise, which in turn result in irritation and annoyance among the workers. The factory in focus has 36 such moulds and when in operation, they generate noise of substantially high levels.

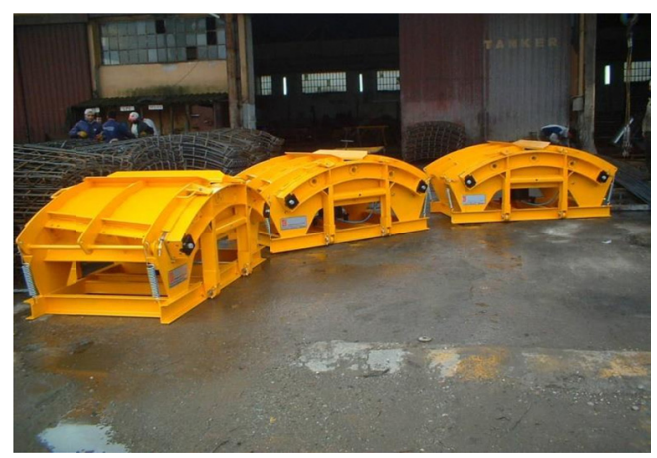

Figure 1. Typical segment moulds

\section{Methodology}

The present study aims to assess the noise levels in a factory of a construction project, the impact of exposure to that noise on the staff and propose ways to lower the noise level. In order to be organized in the approach, details from the construction staff regarding the noise and its impact on their daily routine were initially gathered. It was done to gauge whether there were any adverse effects of the noise or not?

In order to proceed, a survey was conducted among 37 workers (from day and night shifts, combined). For conducting the survey, a questionnaire consisting of 9 questions was prepared. Apart from these 9 questions, the age of the participants was noted as well, so as to ensure that the responses were not age induced. The questionnaire consisted of questions concerning the various adverse effects of noise or improper acoustics, hearing deficiency (Hamernik \& Qiu, 2001), task interference (Suter, 2002), hindrance in communication (Suter, 
2002; Neitze, Seixas, Camp, \& Yost, 1999), annoyance (Ouis, 2001), experiencing stress and hypertension at work (Gerhart, Rainer, \& Holger, 2015; Chang, Beelen, Li, Chen, Lin, Bad, \& Liu, 2014) and disturbance in sleep and heart rates (Pedersen, Health aspects associated with wind turbine noise, 2011; Bakker, Pedersen, van den Berg, Stewart, \& Lok, 2012). For making it easier, the participants were asked to rate these ailments in the frequency of their occurrence. So a 5 point Likert Scale was adopted, with 1 indicating rarely and 5 indicating very frequently. Once results of all the 37 surveys were obtained, they were compiled for calculating the mean and standard deviation for the responses received. They were calculated to establish uniformity between the responses.

The second objective of the research was to study the noise levels in the factory. A simulation software, "i-Simpa" was employed for obtaining noise levels. i-Simpa is open source software dedicated to modelling of sound propagation in 3D complex domains. The software required a model of the precast factory, with the sound absorption coefficients of the boundaries (walls, floor and ceiling), noise sources with their locations and acoustic properties (sound spectrum) as inputs. The sound spectrum was measured with a Sound Level Meter. Sound Level Meter is a measuring instrument used to assess sound or noisy levels by measuring sound pressure. A "fitting zone" was then defined, encompassing all the thirty six noise emitters. The fitting zone defines a volume of geometry that contains scattering objects, producing acoustic diffusion. A surface receiver was created to record noise level at the average ear level across various locations in the factory, i.e., noise mapping, a very efficient noise assessment tool. This model was the base model.

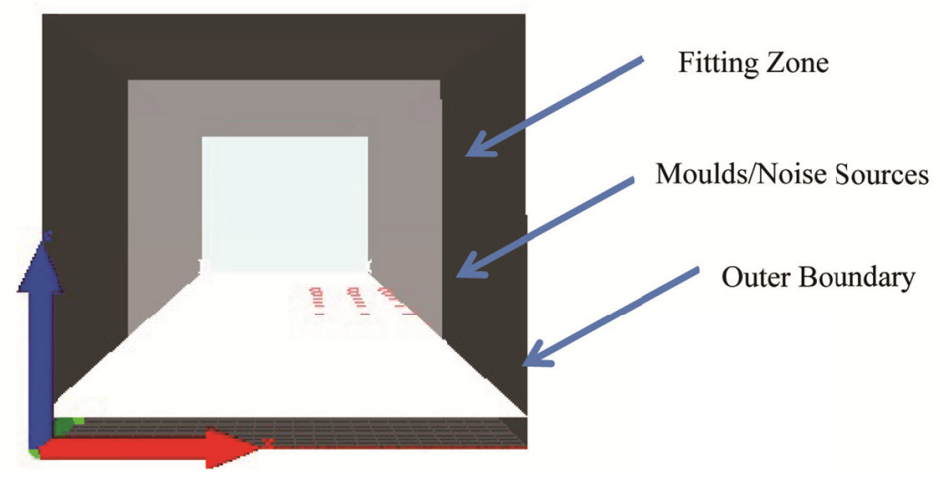

Figure 2. Base model

After creating the model with all the required inputs, calculations were performed in i-Simpa. There are two methods to perform calculations, TCR and SPPS, the latter was opted for calculations. The noise map was obtained after completion of the calculations. The noise map displayed the different noise levels across the factory. It was further aimed to reduce these levels. Reduction was achieved by using insulating materials for boundaries with higher absorption coefficients, as only the damping mechanism (through acoustic absorption of the boundary elements) would lead to lowered sound levels on a larger (Hornikx, 2016; Kang, 2002; Hornikx, 2009; Hornikx, 2011; Hornikx, 2009). To arrive at a comprehensive solution, two further simulations were performed by employing two most commonly used sound insulators, Rockwool and Glass Wool (Mineral Wool and Fiber Glass, respectively). The acoustic properties of both the wools are different which aided in choosing the most effective insulator for the intended purpose.

\section{Results}

\subsection{Questionnaire}

The questionnaire survey conducted to assess the health impacts of the exposed noise on the construction staff working in the factory consisted of 9 questions, each concerning a particular ill effect of noise exposure. Apart from these, the age of the participants was inquired as well. The age classification of the participants was as follows:

Table 1. Age classification among participants

\begin{tabular}{lll}
\hline Age Group & No. of Participants & Percentage of Participants \\
\hline $20-30$ & 15 & 41 \\
$30-40$ & 18 & 48 \\
$>40$ & 4 & 11 \\
\hline
\end{tabular}


Therefore, majority of the participants $(89 \%)$ were under the age of 40 . And hence, the chances of the responses to the questions being age driven were low. The mean and standard deviations for the other responses were as follows:

Table 2. Compiled responses to questionnaire

\begin{tabular}{llll}
\hline Classification & Parameter & Mean & Standard Deviation \\
\hline \multirow{2}{*}{ Auditory Examination } & Difficulty in Hearing & 4.65 & 0.48 \\
& Access to Proper Headgear & 1.25 & 0.43 \\
\multirow{2}{*}{ Task Interference } & Hampers Productivity & 3.46 & 0.99 \\
& Difficulty in Communication & 4.3 & 0.71 \\
\multirow{3}{*}{ Personal Behavior } & Annoyance & 4.52 & 0.51 \\
& Hypertension & 2.49 & 0.96 \\
\multirow{2}{*}{ Physiological Effects } & Stress & 2.98 & 0.83 \\
& Irregularities in Heart Beat Pattern & 2.71 & 0.99 \\
& Sleep Disorder & 4.03 & 0.60 \\
\hline
\end{tabular}

These figures clearly reflect that the prevailing acoustics in the factory were very poor, leading to increased Working Level Noise (Gerhart Tieslera, Rainer Machnerb, Holger Brokmannb 2015) and distress among the workers. Some of the responses like those for Difficulty in Hearing, Communication, Annoyance and Sleep Disorder were quite alarming and prompted for an immediate assessment of noise level and its subsequent reduction.

\subsection{Assessment of Noise Level}

\subsubsection{Sound Spectrum of Sound Sources}

Sound Spectrum was required for defining the acoustic properties of the noise sources, which would be inputs for calculation of the Noise Levels in i-Simpa. The sound spectrum of the sound sources was measured by a Sound Level Meter. The readings were taken by holding the instrument close to the sound sources. Five sets of measurements were taken. The average of the readings obtained was:

Table 3. Sound spectrum of sound sources

\begin{tabular}{lll}
\hline Frequency $(\mathrm{Hz})$ & $\mathrm{dB}$ & $\mathrm{dB}(\mathrm{A})$ \\
\hline 50 & 69.2 & 39 \\
63 & 69.2 & 43 \\
80 & 69.2 & 46.7 \\
100 & 69.2 & 50.1 \\
125 & 72.5 & 56.4 \\
160 & 74.9 & 61.5 \\
200 & 77.9 & 67 \\
250 & 79 & 70.4 \\
315 & 81.5 & 74.9 \\
400 & 83.2 & 78.4 \\
500 & 84.9 & 81.7 \\
630 & 86.3 & 84.4 \\
800 & 88.5 & 87.7 \\
1000 & 91.4 & 91.4 \\
1250 & 89.2 & 89.8 \\
1600 & 87.7 & 88.7 \\
2000 & 85.1 & 86.3 \\
2500 & 82.8 & 84.1 \\
3150 & 81.5 & 82.7 \\
4000 & 78.9 & 79.9 \\
5000 & 76.8 & 77.3 \\
6300 & 76.8 & 76.7 \\
8000 & 76.8 & 75.7 \\
10000 & 76.8 & 74.3 \\
12500 & 76.8 & 72.6 \\
16000 & 76.8 & 70.1 \\
20000 & 76.8 & 67.5 \\
\hline
\end{tabular}




\subsubsection{Base Model}

The base model was modelled as close to the real factory as possible with all the material properties remaining unaltered. After running the calculations for the base model, the following noise map was obtained:

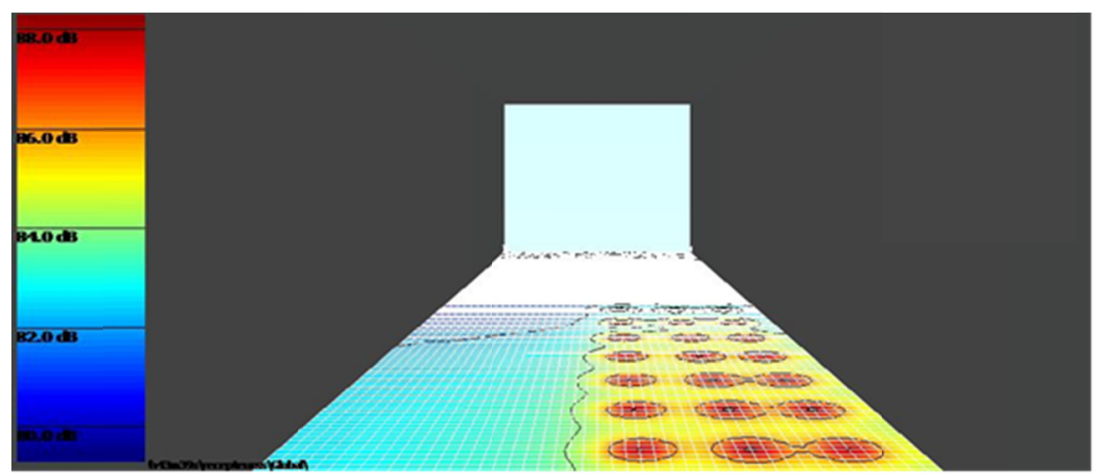

Figure 3. Base model

The results reveal a noise level greater than $85 \mathrm{~dB}$ all around the sources. Even at the extreme boundary, the level decreases only to $82 \mathrm{~dB}$. As per the National Institute of Deafness and Other Communication Disorders, long or repeated exposures to sounds at or above $85 \mathrm{~dB}$ can cause hearing loss. Therefore, continual and repeated exposure to these levels over 6 days a week is bound to result in certain auditory ailments. Hence, such a situation warrants remedial action.

\subsection{Subsequent Models for Noise Reduction}

The subsequent models (Rockwool and Glass wool) were constructed with altered boundary properties (absorption coefficients). The absorption coefficients for both are as follows:

Table 4. Absorption coefficients of mineral wools

\begin{tabular}{lllllll}
\hline Frequency & $125 \mathrm{~Hz}$ & $250 \mathrm{~Hz}$ & $500 \mathrm{~Hz}$ & $1000 \mathrm{~Hz}$ & $2000 \mathrm{~Hz}$ & $4000 \mathrm{~Hz}$ \\
\hline Rockwool & 0.15 & 0.6 & 0.9 & 0.9 & 0.9 & 0.85 \\
Glass Wool & 0.2 & 0.55 & 1 & 1 & 1 & 1 \\
\hline
\end{tabular}

\subsubsection{Rockwool}

The model with Rockwool generated the following noise map.

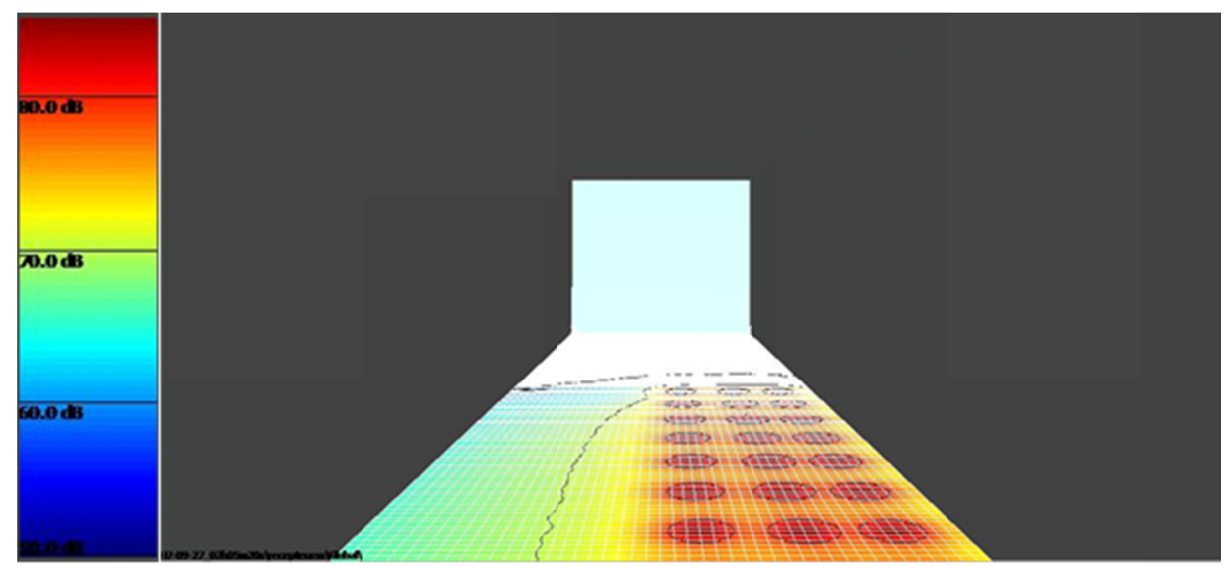

Figure 4. Rockwool model 
These results divulge that the noise levels around the sources reduced to the range of $75-80 \mathrm{~dB}$. This reduction of $5-10 \mathrm{~dB}$ would result in a significant perceived volume reduction of $35-45 \%$.

\subsubsection{Glass Wool}

The Glass wool model, on the other hand, generated the following map.

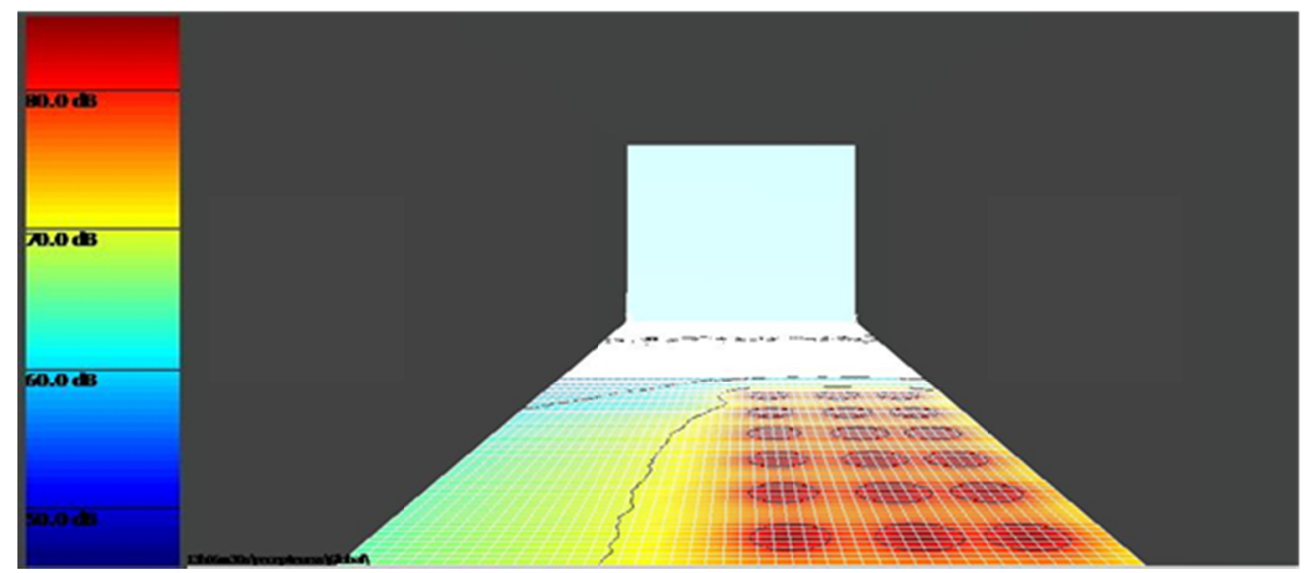

Figure 5. Glass wool model

Although the absorption coefficients for both, Rockwool and Glass Wool were different, it has been discovered that the noise levels are reduced to similar levels. Hence, it was concluded that noise levels cannot be significantly lowered below the obtained range.

\section{Discussion and Conclusion}

The responses from the factory staff disclosed the distress among them. Most of the responses to ill-effects of noise were on the higher side of the range with little deviation from one response to another. This revealed that the workplace environment was not appropriate for the rigorous activities carried out by the staff, and hence, the situation demanded a noise assessment of the factory.

The calculations for the base model revealed that the noise levels in the factory were as high as $90 \mathrm{~dB}$, which exceed the limit of $70 \mathrm{~dB}(\mathrm{~A})$, for almost all frequency levels, set by the Central Pollution Control Board, India for industrial areas. This coupled with the responses from the questionnaire urged the construction firm in focus to venture for possible solutions to abate noise levels. Hence, sound absorption mechanism for boundary elements was adopted.

The calculations for revised models with altered acoustic properties (Rockwool and Glass wool) of boundary elements of the factory however revealed unanticipated results. Both the models reduced noise to same levels leading to the conclusion that the noise levels could not be reduced further. Therefore, both the wools were found to be equally effective. It was hence proposed that either could be used to reduce the perceived noise levels.

Additionally, due to the rapid pace of development observed in the developing countries of late, noise pollution has become a dominant threat that mankind faces and the cost of reducing it in the future shall get exorbitant (Joshi, Devkota, Chamling, \& Shrestha, 2003). Hence, it warrants immediate action.Since, quality of life being offered to the residents is an important criterion for sustainable cities, noise and its health impacts must therefore be considered as quality of life indicators in sustainable cities.

\section{References}

Bakker, R. H., Pedersen, E., van den Berg, G. P., Stewart, R. E., \& Lok, W. (2012). Impact of wind turbine sound on annoyance, self-reported sleep disturbance and psychological distress. J. Sci. Total Environ., 15, 42-51.

Chang, T. Y., Beelen, R., Li, S. F., Chen, T. I., Lin, Y. J., Bad, B. Y., \& Liu, C. S. (2014). Road traffic noise frequency and prevalent hypertension in Taychung, Taiwan: A cross sectional study. Environ. Health 2014.

Chedd, G. (1981). Sound from communication to noise pollution. Science, 211, 1450-1452.

Coelho, J. L. B., \& Alarcao, D. (2006). Noise mapping and noise action plans in large urban areas. TechniAcoustica. 
European Centre for Environment and Health, World Health Organization. (2001). Burden of Disease from Environmental Noise: Quantification of Healthy Life Years Lost in Europe.

Gerhart, T., Rainer, M., \& Holger, B. (2015). Classroom Acoustics and Impact on Health and Social Behaviour, 6th International Building Physics Conference. IBPC 2015 Energy Procedia 78(2015), 3108-3113

Hamernik, R. P., \& Qiu, W. (2001). Energy-independent factors influencing noise-induced hearing loss in the chinchilla model. J. Acoust. Soc.Am., 110. https://doi.org/10.1121/1.1414707

Hornikx, M. (2009). Numerical Modeling of Sound Propagation to Closed UrbanCourtyards (PhD Thesis). Chalmers University of Technology, Sweden.

Hornikx, M. (2016). Ten questions concerning computational urban acoustics. Building and Environment, 106, 409-421. https://doi.org/10.1016/j.buildenv.2016.06.028

Hornikx, M., \& Forssen, J. (2009). Noise abatement schemes for shielded canyons. Appl.Acoust., 70, 267-283. https://doi.org/10.1016/j.apacoust.2008.04.002

Hornikx, M., \& Forssen, J. (2011). Modelling of sound propagation to three-dimensionalurban courtyards using the extended Fourier PSTD method. Appl. Acoust., 72(9), 665-676. https://doi.org/10.1016/j.apacoust.2011.03.005

http://i-simpa.ifsttar.fr/

http://i-simpa-wiki.readthedocs.io/en/latest/project_window.html\#fitting-zone

http://i-simpa-wiki.readthedocs.io/en/latest/project_window.html\#calculation-tab

http://www.acoustic.ua/st/web_absorption_data_eng.pdf

http://www.envfor.nic.in/citizen/specinfo/noise.html

https://svetlanaroit.files.wordpress.com/2009/11/visual_values2.pdf

https://www.acousticalsurfaces.com/soundproofing_tips/noise_reduction.htm

https://www.pce-instruments.com/english/measuring-instruments/test-meters/sound-level-meter-noise-level-mete r-kat_40095_1.htm

https://www.simplypsychology.org/likert-scale.html

Joshi, S. K., Devkota, S., Chamling, S., \& Shrestha S. (2003). Environmental noise induced hearing loss in Nepal, Kathmandu University. Medical Journal, 1, 177-183.

Kang, J. (2002). Numerical modelling of the sound fields in urban streets with diffusely reflecting boundaries. $J$. Sound. Vib., 258(5), 793-813. https://doi.org/10.1006/jsvi.2002.5150

Kantova, R. (2016). Construction Machines as a Source of Construction Noise, Structural and Physical Aspects of Construction Engineering.

Kenney, G. D., \& Ayer, H. E. (1975). Noise exposure and hearing levels of workers in thesheet metal construction trade. Am IndHygAssoc J, 36, 626-32.

Kenney, G. D., Ayer, H. E. (1975). Noise exposure and hearing levels of workers in thesheet metal construction trade. Am IndHygAssoc J, 36, 626-632.

LaBenz, P., Cohen, A., \& Pearson, B. (1967). A noise and hearing survey of earth-movingequipment operators. Am IndHygAssoc J, 28, 117-128. https://doi.org/10.1080/00028896709342495

Luman, M. (2016). Noise Induced Hearing Loss in Construction. Retrieved from https://safetyequipment.org/knowledge-center-items/noise-induced-hearing-loss-construction

Lusk, S. L., Hong, O. S., Ronis, D. L., Eakin, B. L., Kerr, M. J., \& Early, M. R. (1999). Effectiveness of anintervention to increase construction workers' use of hearing protection. HumFactors, 41, 487-494.

McClymont, L. G., \& Simpson, D. C. (1989). Noise levels and exposure patterns to do-it-yourself power tools. $J$ LaryngolOtol, 103, 1140-1141. https://doi.org/10.1017/S0022215100111211

National Institute on Deafness and Other Communication Disorders. (2017). Noise induced hearing loss. Retrieved from https://www.nidcd.nih.gov/health/noise-induced-hearing-loss

Neitzel, R., Seixas, N. S., Camp, J., \& Yost, M. (1999). An assessmentof occupational noiseexposures in four construction trades. Am IndHyg Assoc J, 60, 807-817. https://doi.org/10.1080/000288999008984506

Nelson, D. I., Nelson, R. Y., Concha-Barrientos, M., \& Fingerhut, M. (2005). The globalburden of occupational 
noise-induced hearing loss. Am. J. Ind. Med. 48, 446-458. https://doi.org/10.1002/ajim.20223

Nixon, C., Johnson, D., \& Stephenson, M., (1977). Asymptotic behavior of temporarythreshold shift and recovery from 24 to 48 hour noise exposures. Aviat. SpaceEnviron. Med., 48(April), 311-515.

Ouis, D. (2001). Annoyance from road traffic noise: a review. Journal of Environmental Psychology, 21, 101-120. https://doi.org/10.1006/jevp.2000.0187

Pedersen, E. (2011). Health aspects associated with wind turbine noise-Results from three field studies. Noise Control Eng. J., 59, 47-53. https://doi.org/10.3397/1.3533898

Salomons, E. (n. d.) Traffic noise control and sustainable urban planning. Retrieved from http://www.qside.eu/urban_sus.html

Smith, M. G., Croy, I., Ogren, M., \& PerssonWaye, K. (2013). On the influence of freight trains on humans: A laboratory investigation of the impact of nocturnal low frequency vibration and noise on sleep and heart rate. PLoS ONE 2013. https://doi.org/10.1371/journal.pone.0055829

Suter, A. H. (2002). Construction noise: exposure, effects, and the potential for reme-diation; a review and analysis. Am IndHygAssoc J, 63, 768-789. https://doi.org/10.1080/15428110208984768

Ward, W. D. (1976). A Comparison of the Effects of Continuous, Intermittent, and Impulse Noise. In D. Henderson, R. Hamernik, D. S. Dosanjh, \& J. H. Mills (Eds.), Effects of Noise on Hearing (pp. 407-420). New York: Raven Press.

World health Organization-regional office for Europa, JRS European Committee: Burden of disease from Environmental Noise, quantification of healthy life years lost in Europa, 2011. Retrieved from http://www.euro.who.int/_data/assets/pdf_file/0008/136466/Burden_of_Disease.pdf

\section{Copyrights}

Copyright for this article is retained by the author(s), with first publication rights granted to the journal.

This is an open-access article distributed under the terms and conditions of the Creative Commons Attribution license (http://creativecommons.org/licenses/by/4.0/). 